\title{
JUSTIÇA FISCAL E A COOPERATIVA DE CRÉDITO MÚTUO DOS MEMBROS DA MAGISTRATURA, MINISTÉRIO PÚBLICO, E DEFENSORIA PÚBLICA DO ESTADO DO MARANHÃO: SOBRAS LÍQUIDAS E A PRÁTICA DE CONDUIT SHELLS - UM ESTUDO DE CASO
}

FISCAL JUSTICE AND THE MUTUAL CREDIT COOPERATIVE OF MEMBERS OF THE JUDICIARY BRANCH, PUBLIC MINISTRY, AND PUBLIC DEFENSE OFFICE OF THE STATE OF MARANHÄO: SOBRAS LÍQUIDAS AND CONDUIT SHELLS PRACTICE - A CASE STUDY

Hélder Machado Passos

Doutor em Filosofia pela Universidade de São Paulo; Tutor do Programa de Educação Tutorial (PET) do curso de Direito da Universidade Federal do Maranháo passos_helder@yahoo.com.br

Pedro Nilson Moreira Viana Graduando em Direito pela Universidade Federal do Maranhão, Pesquisador do Programa de Educação Tutorial (PET) do curso de Direito da Universidade Federal do Maranháo pedro.moreira.viana@hotmail.com

\section{RESUMO}

Em que pese ter a Constituição Federal de 1988 assegurando inúmeros benefícios legais às Associaçóes Cooperativas - dentre os quais se destacam a autonomia gerencial, a proteção regulatória, e o incentivo fiscal, é imprescindível analisar, a partir do cenário macroeconômico atual, em que medida a isenção tributária dos atos cooperativos se insere no plano específico das Cooperativas de Crédito Mútuo. Neste aspecto, em breve síntese, o objetivo central do presente estudo é apresentar, sob o prisma descritivo/exploratório, o caso COOMAMP vs. Fazenda Nacional a fim de analisar os limites materiais e processuais da isenção tributária dos atos cooperativos, identificando para tanto, as diferenças conceituais entre atos cooperativos próprios e impróprios, e sua relação com o fenômeno do aumento patrimonial mascarado - o intitulado "conduit shell".

Palavras-chave: Cooperativas de Crédito. Limites à isenção tributária. Conduit Shell. 


\section{ABSTRACT}

Despite the numerous legal benefits assured by the Constitution to the Cooperatives Associations, among which are notable the management autonomy ang regulatory protection, it is imperative to analyze, from the current macroeconomic scenario, to what extent does the "tax free policy" of cooperative acts is included in the specific plan of Financial Cooperatives. In this aspect, in synthesis, the central objective of the present study is to present, under the descriptive/exploratory prism, the COOMAMP vs. National Treasury case in order to analyze the material and procedural limits of the tax exemption of cooperative acts, thus identifying the conceptual differences between own and improper cooperative acts, and its relation to the masked patrimonial phenomenon - the so-called "conduit shell.

Keywords: Financial Cooperatives. Limits to the fiscal exemption. Conduit Shell.

\section{INTRODUÇÁO}

Os inescapáveis combates entre as forças de capital e suas responsabilidades sociais sempre revolveram ao espaço jurídico na alternativa de encontrar um campo fértil de soluçōes para reorganização dos agentes e fatores econômicos em torno de um ideal de desenvolvimento socialmente sustentável. Nesse interminável conflito, a incursão de valores sociais na macroestrutura econômica representa ao passo que um considerável avanço civilizatório, um mecanismo de refreamento às inúmeras distorções de um mercado de práticas predatórias.

Nesse breve contexto, o Cooperativismo surge positivado na Constituição da República como instrumento chave de consolidação do valor humano na relação capital v. social, na medida em que garante à sociedade civil inúmeras possibilidades de auto-organizaçấo produtiva.

Assim, a disciplina conferida pela Constituição da República Federativa do Brasil de 1988 (CRFB) à matéria cooperativista propicia um ambiente equilibrado para o desenvolvimento da autonomia de tais associaçóes, assegurando, além disso, o devido estímulo regulatório de sua instituição nas políticas de desenvolvimento do pleno emprego e da economia - 
por meio das conhecidas cooperativas de crédito. ${ }^{1}$

Contudo, em que pese ter a Constituição conferindo especial tratamento a tais cooperativas, não raro, tais entidades são utilizadas como "instrumentos de mera exploração econômica, isto é, 'conduit shells', para unir tratamento regulatório-tributário favorecido ao singelo aumento patrimonial individual." ${ }^{2}$ Neste aspecto, o presente estudo pretende analisar o caso COOMAMP vs. Fazenda Nacional submetido à apreciação da 5a Vara Cível da Seção Judiciária Federal do Estado do Maranhão nos autos da ação ordinária n. 0036147 90.2015.4.01.3700.

No referido caso, em breve síntese, a Fazenda Nacional no bojo de sua atuação tributáriofiscalizatória, procedeu ao lançamento de Imposto de Renda Complementar sobre as sobras líquidas distribuídas entre os membros da Cooperativa de Crédito Mútuo da Magistratura, do Ministério Público, da Procuradoria Geral do Estado, da Defensoria Pública e respectivos servidores - COOMAMP.

Assim, a partir de um estudo essencialmente teórico, sob o prisma descritivo/exploratório do caso supracitado, pretende-se identificar os elementos controvertidos que levam inescapavelmente à reanálise dos benefícios fiscais/regulatórios conferidos às Cooperativas de crédito, ante o destacamento de atos cooperativos próprios/impróprios, e o fenômeno do conduit shells.

\section{BREVE DELIMITAÇÁO SUBJETIVA E OBJETIVA DO CONFLITO: A POSSIBILIDADE DE TRIBUTAÇÃO DE ATOS COOPERATIVOS IMPRÓPRIOS}

De efeito, a Cooperativa de Crédito Mútuo da Magistratura, do Ministério Público, da Procuradoria Geral do Estado, da Defensoria Pública e respectivos servidores, doravante - COOMAMP, propôs ação ordinária em face da Fazenda Nacional em 5 de maio de 2015 pretendendo a "declaração de inexistência de relação jurídica tributária a impor a retenção do imposto de renda à razão de 15\% (quinze por cento), sobre as sobras líquidas distribuídas entre os membros cooperados."

A Cooperativa Autora, nas razóes iniciais, sustentou ser ilegal a incidência de Imposto de

1 BRASIL. Constituição da República Federativa do Brasil, 1988, artigo 192 .

2 BRASIL. Supremo Tribunal Federal. Recurso Extraordinário no 672.215/RG, 2012. 
Renda Retido na Fonte (IRRF) sobre as rendas advindas das sobras líquidas dos valores arrecadados dos cooperados, eis que ante o dispositivo do Artigo 79 da Lei n. ${ }^{0}$ 5.764/71, a divisão de tais valores apurados no exercício financeiro do calendário base 2014 são atos cooperativos puros, sendo, portanto, submetidos às regras de tributação distintas.

I.e, segundo tal intelecção, a restituição das parcelas de integralização de capital promovidas a maior pelos cooperados ao longo do exercício financeiro, significaria simples retorno remuneratório em função da redução de despesas operacionais e do excesso financeiro empregado pelo cooperado na cooperativa, não havendo que empregar sentido diverso à natureza do ato cooperativo próprio, a fim de permitir a incidência do IRRF.

Noutro modo, a despeito da pretensão declaratória inicial, a Fazenda Nacional propugna tese diversa.

Em rápida síntese, sustenta que as cooperativas de crédito atuam no mercado como verdadeiras instituiçôes financeiras de sorte, que seus cooperados "nada mais são do que aplicadores de recursos". Pelo aduzido assim, os cooperados utilizar-se-iam da referida entidade para obter receitas para além daquelas resultantes das operaçóes de crédito intercooperadas.

Ademais, a Fazenda Nacional sustentou que diante da estrutura funcional da COOMAMP, a partir da leitura sistemática de seu estatuto social, é possível verificar que as sobras líquidas em questão não necessariamente decorreram da devolução de recursos cooptados e não utilizados ao longo do exercício financeiro, mas que também resultaram de operaçóes mercantis, e.g. aplicaçóes financeiras ou empréstimos realizados pela cooperativa - que náo se classificam como ato cooperativo puro, posto que realizados com terceiros náo associados.

Assim, tendo as sobras líquidas do caso em estudo potencialmente sido integralizadas mediante operaçóes de mercado, sujeitar-se-iam às regras de tributação relativas às aplicaçôes financeiras de renda fixa (Lei n. ${ }^{\circ} 8.981 / 95$ Artigo $65 \$ 7^{\circ}$ b e $\$ 8^{\circ}$ ), devendo integrar a base de cálculo do imposto de renda.

Essa a quadra, resta, por derradeiro, analisar os pontos relativos à pretensa prática de conduit shelle as divergências principais dentre os atos cooperativos próprios e impróprios, bem como sua relação com a natureza sui generis das cooperativas de crédito. 
Pois bem.

Da leitura de seu ato constitutivo, é possível identificar que a COOMAMP qualificase como cooperativa de crédito mútuo, destinada em grande medida, à prestação de serviços financeiros exclusivamente a seus cooperados por meio da captação de recursos (i) oriundos de depósitos à vista e a prazo; (ii) de instituiçóes financeiras, na forma de empréstimos ou outras operaçóes de crédito; e ainda (iii) de doaçóes, empréstimos ou repasses de quaisquer entidades.

Como de regra, a partir do mencionado, a distribuição das sobras líquidas dos valores auferidos pelas Cooperativas, apresenta-se na fórmula inserta no artigo $4^{\circ}$ VII da Lei n.5.764/71 - estabelecida a fim de que as parcelas de integralização de capital promovidas a maior pelos cooperados ao longo do exercício financeiro possam ser restituídas aos associados. Veja-se:

Art. $4^{\circ}$ As cooperativas são sociedades de pessoas, com forma e natureza jurídica próprias, de natureza civil, não sujeitas a falência, constituídas para prestar serviços aos associados, distinguindo-se das demais sociedades pelas seguintes características: (...)

VII - retorno das sobras líquidas do exercício, proporcionalmente às operaçóes realizadas pelo associado, salvo deliberação em contrário da Assembléia Geral; (...)

Portanto, em um primeiro aspecto, sobras líquidas devem ser entendidas como recursos que advêm da realização de atos cooperativos, quando se verifica um resultado positivo obtido na relação entre as receitas e as despesas efetuadas pela sociedade cooperativa no exercício financeiro. ${ }^{3}$

Melhor explica Walmor Franke que, em poucas palavras, define:

Nas cooperativas que operam em círculo fechado com os associados, as diferenças entre receita e despesa, apuradas nos balanços anuais, quando positivas, podem ter aparência de lucro. Na realidade, porém, trata-se de 'sobras' resultantes de haver o associado pago a mais pelo serviço que a cooperativa lhe prestou ou, inversamente, de ter ela retido um valor excessivo como contraprestaçáo o serviço fornecido. ${ }^{4}$

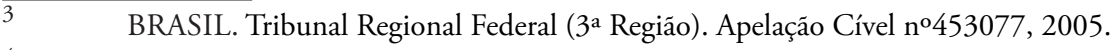

4 FRANKE, W.. Direito das sociedades cooperativas, 1973, p.19. 
É dizer-se assim, que o conceito de ato cooperativo próprio não pode ser teoricamente assemelhado ao conceito operaçáo mercantil comum, de sorte que nestes atos, realizados entre a Cooperativa e a pessoa de seus cooperados, é absolutamente defesa a incidência tributária. Dessa forma, manifestando consenso doutrinário, Renato Lopes Becho, define ato cooperativo próprio nos seguintes termos :

(...) definimos os atos cooperativos como os atos jurídicos que criam, mantém ou extinguem relaçóes cooperativas, exceto a constituição da própria entidade, de acordo com o objeto social, em cumprimento de seus fins institucionais(... $)^{5}$

Com efeito, os ditos atos cooperativos - que, em primeiro momento, se amoldam à figura da redistribuição das sobras líquidas - são insuscetíveis de tributação em virtude do mandamento encartado na Constituição da República que exige da lei tratamento "estimulante e amparador" com o fito de promover o espírito corporativista.

Sobre o tema, melhor ensina Teori Albino Zavascki, quando do voto condutor em sede do Recurso especial 591298/MG , que apesar de tratar sobre incidência tributária do PIS e COFINS, amolda-se com perfeição à questão controvertida em estudo. Em bom tempo, asseverou:

(...) $[\mathrm{A}]$ reuniáo em cooperativa não pode implicar em maior carga tributária do que a resultante da ação isolada dos cooperados. Se cooperativar-se viesse a gerar mais tributos do que a ação isolada haveria desestímulo ao cooperativismo o que conflita com o $2^{\circ}$ do artigo 174 da CF/88"(p. 61). Diante de todo esse panorama, a discussão relativa à Lei n. ${ }^{\circ} 9.718 / 98$ torna-se desnecessária, pois qualquer que seja o conceito de faturamento (equiparado ou não a receita bruta), tratando-se de ato cooperativo típico, náo ocorrerá o fato gerador do PIS por ausência de materialidade sobre a qual possa incidir essa contribuição social (...)

No excerto, Teori Zavascki ${ }^{6}$ expressou o entendimento uníssono da jurisprudência pátria, no qual as cooperativas ao prestar serviços aos seus próprios cooperados, sem qualquer interesse negocial ou lucrativo, dispóem de absoluta isenção tributária haja vista que sua razão essencial de existência reside em servir os associados, à espécie, proporcionando

5 BECHO, R. L. Tributaçáo das Cooperativas, 2004, p.145

6 BRASIL.Supremo Tribunal Federal. Recurso Extraordinário no 591.298/MG. Relator: Ministro Teori Albino Zavascki, 2005 p. 136. 
"através da mutualidade, assistência financeira aos associados em suas atividades específicas.”

Impóe-se, noutro modo, verificar que não são todas as receitas auferidas pelas Cooperativas albergadas pela isenção tributária. Neste aspecto, o artigo 111 da Lei n. 5.764/71 preceitua que são consideradas rendas tributáveis os resultados positivos obtidos pelas cooperativas nas operaçóes de aquisição de produtos ou de fornecimento de bens e serviços a não associados (artigos 85 e 86) e de participação em sociedades não cooperativas (artigo 88), assim dispondo:

Art. 85. As cooperativas agropecuárias e de pesca poderão adquirir produtos de náo associados, agricultores, pecuaristas ou pescadores, para completar lotes destinados ao cumprimento de contratos ou suprir capacidade ociosa de instalaçóes industriais das cooperativas que as possuem.

Art. 86. As cooperativas poderão fornecer bens e serviços a não associados, desde que tal faculdade atenda aos objetivos sociais e estejam de conformidade com a presente lei.

\section{(...)}

Art. 111. Serão considerados como renda tributável os resultados positivos obtidos pelas cooperativas nas operaçóes de que tratam os artigos 85, 86 e 88 desta Lei.

Os mencionados dispositivos exemplificam que no campo da exação tributária brasileira, é imprescindível a distinção entre os atos cooperativos i) por meio dos quais as sociedades cooperativas atingem suas finalidades sociais pelo relacionamento direto com os cooperados; e ii) os atos não cooperativos, estes, que não atingem as finalidades institucionais, eis que realizados com terceiros não cooperados e portanto, não albergados pelo manto da imunidade tributária - sendo assim, geradores de tributação.

No que concerne à Cooperativa de Crédito Mútuo em questão, verifica-se um ponto específico que confere, muito certamente, razão à tese da Fazenda Nacional.

É que na forma do estabelecido pelo estatuto social da Cooperativa de Crédito em estudo, apesar das operações de captação de recurso; e as de concessão de crédito, serem praticadas em relação a seus cooperados, exclusivamente, a COOMAMP pode praticar todas as operaçóes típicas de sua modalidade social quanto à captaçáo de recursos, por meio de atos consistentes "em doaçóes, empréstimos ou repasses, em caráter eventual, isentos de remuneração ou a taxas favorecidas, de qualquer entidade.” 
I.e. as receitas patrimoniais da Cooperativa autora se integram por meio de um método complexo, ou seja, de valores transferidos tanto pelos cooperados quanto por terceiros - por meio de operaçóes de crédito, estas, de natureza essencialmente mercantil. Por oportuno, veja-se o que dispóe no artigo $2^{\circ} \$ 1^{\circ}$ do Estatuto COOMAMP:

\section{(...)}

Art.2० A COOMAMP tem por objetivos sociais: (...)

$\$ 1^{\circ}$ - A COOMAMP, para a consecução de seus objetivos, poderá praticar todas as operações típicas de sua modalidade social, consistentes em:

I. captação de recursos:

a) exclusivamente de associados, oriundos de depósitos à vista e depósitos a prazo sem emissão de certificados;

b) de instituiçôes financeiras, nacionais ou estrangeiras, na forma de empréstimos, repasses, refinanciamentos e outras modalidades de operação de crédito;

c) de qualquer entidade, na forma de doaçóes, de empréstimos ou repasses, em caráter eventual, isentos de remuneração ou a taxas favorecidas

II. participação do capital de:

a) cooperativa central de crédito;

b) instituição financeira controlada pela central;

c) cooperativas, ou empresas controladas pela Central, que atuem na prestação de serviços e fornecimento de bens exclusivamente ao setor cooperativo;

d) entidades de representação institucional, de cooperação técnica ou educacional

Neste ponto reside a impertinência do pleito autoral de ver declarada a inexistência de relação jurídico-tributária na retenção de imposto de renda derivado da distribuição das sobras líquidas em questão. É que vez verificada a autorização estatutária de integralização de capital por meio de operaçóes mercantis com qualquer entidade não-cooperada, os valores concernentes às sobras líquidas podem, ou não, ser senão parcialmente, compostos de valores relativos a empréstimos ou qualquer outra operação de crédito firmada com terceiro. 


\section{CONSIDERAÇÓES FINAIS}

Ante o exposto, verifica-se que por pender sobre tais recursos, razoável dúvida quanto à origem integral-cooperativa própria ou imprópria, não há ilegalidade na pretensão Fazendária de determinar à COOMAMP a retenção direta na fonte de parte dos recursos a título de imposto de renda, eis que em desabono da pretensão autoral - por apresentarem nítida feição mercantil - os atos não puramente cooperativos geram receita e faturamento para a sociedade cooperativa. Tal resultado positivo, como preliminarmente alinhavado, segundo a previsão do artigo 87 da Lei n. ${ }^{0}$ 5.764/71, é passível sim de tributação.

Refrear a pretensão da Fazenda Nacional seria, ainda que indiretamente, propiciar aos Cooperados evolução patrimonial indevida, posto que do tratamento regulatóriotributário distinto conferido às Cooperativas de Crédito - que afasta, em um primeiro aspecto, a incidência de tributos v.g. o Imposto sobre a Renda -, os Cooperados seriam, hipoteticamente, restituídos de numerários dos quais não integralizaram mediante o pagamento periódico de quotas de participação.

Em verdade, ad argumentadum tantum, é plenamente possível que a Cooperativa de Crédito obtivesse por meio de um empréstimo, doação, ou outra operação de crédito com terceiro, vultuosa porção patrimonial - vez que autorizada pela norma estatutária, e, no final do exercício financeiro, a pretexto de distribuir as sobras excedentes, revertesse tais ganhos aos Cooperados sem que, contudo, fossem regularmente tributados. Nisso consiste a mais precisa definiçáo do fenômeno econômico a que se referiu o Ministro Joaquim Barbosa no Recurso Extraordinário n. 672.215/RG. Nessa esteira, calha apresentar o pronunciamento da Desembargadora Federal Theresinha Caserta, quando nos autos do Agravo de Instrumento n. ${ }^{\circ}$ 1999.03.00.016281-9, firmou brilhante passagem:

(...) O critério legalmente estabelecido para a aferição da cooperatividade de determinado ato é o subjetivo, isto é, deve-se ter em consideração apenas os sujeitos que o praticam. Em vista disso, para fins de subsunção de um ato como modelo legal, a classificação feita pela agravante não tem utilidade, haja vista ser baseada em aspectos dissonantes do eleito pela lei. O que importa saber é se há ou não participação de não associados. A própria Lei no $5.764 / 71$ permite essa conclusão, pois estabelece em seu artigo 87 que 'os resultados das operaçôes das cooperativas com não associados, mencionados nos artigos 85 e 86, serão levados à conta do Fundo de Assistência Técnica, Educacional e Social e serão contabilizados em separado, de molde a permitir cálculo para a incidência de tributos. 
Assim, deflui ser plausível e contumaz a probabilidade de tais valores concernentes às sobras líquidas serem decorrentes de operaçôes de crédito ativo realizadas com terceiros não-cooperados, de sorte que é imprescindível haver a específica demonstração, in separato, dos rendimentos não-cooperados auferidos.

É que ao se considerar que, pelo menos quanto à escrita contábil, as sociedades cooperativas são equiparadas às demais sociedades (artigo 22 da Lei no 5.764/71), a prova do repasse das "sobras líquidas" deve constar do balanço geral da cooperativa, de forma a se verificar a origem financeira das verbas que compóem o "bolo distribuinte".

Vez não demonstrado, especificamente, a contabilização de tais rendas, ônus processual este incumbido à Cooperativa, impóe-se rejeitar o pleito autoral aqui estudado.

\section{REFERÊNCIAS}

BECHO, R. L. Tributaçáo das Cooperativas. Dialética, 3º Ed. São Paulo: 2004

BRASIL. Supremo Tribunal Federal. Recurso Extraordinário n. 672.215/RG. Relator: Ministro Joaquim Barbosa. Pesquisa de Jurisprudência, Acórdãos, 14 maio 2012.

BRASIL. Constituição (1988). Lex: legislação federal e marginália, São Paulo, v. 98, p. 1966, out./dez. 2017

BRASIL. Lei n. 5.764 de 16 de Dezembro de 1971. Define a Política Nacional de Cooperativismo, institui o regime jurídico das sociedades cooperativas, e dá outras providências. Lex: legislação federal e marginália, São Paulo, v. 90, p. 1654, out./dez. 2015

BRASIL. Lei n. 8.981 de 20 de Janeiro de 1995. Altera a legislação tributária Federal e dá outras providências. Lex: legislação federal e marginália, São Paulo, v. 83, p. 981, out./ dez. 2010.

BRASIL. Supremo Tribunal Federal. Recurso Extraordinário n. 591.298/MG. Relator: Ministro Teori Albino Zavascki. Pesquisa de Jurisprudência, Acórdãos, DJ 07/03/2005 p. 136. 
BRASIL. Tribunal Regional Federal (3. Região.). Apelação Cível n. 453077/SP. Rel. Desembargadora Federal Consuelo Yoshida. São Paulo, 02 de Setembro de 2005.

BRASIL. Tribunal Regional Federal (3. Regiáo.). Agravo de Instrumento n.1999.03.00.016281-9. Rel. Des. Federal Theresinha Caerta. São Paulo, 09 de Agosto de 2012. DJ 03/08/2012, p. 1794.

FRANKE, W. Direito das sociedades cooperativas. São Paulo, 1973, p. 157. 